\title{
Surface Modification of Detonation Nanodiamonds with Platinum and Palladium Nanoparticles
}

\author{
V. G. Isakova ${ }^{1,2}$, V. P. Isakov ${ }^{2}$, A. I. Lyamkin ${ }^{2}$, N. V. Zharikova ${ }^{2}$, A. S. Yunoshev ${ }^{3}$, \& I. V. Nemtsev ${ }^{1}$ \\ ${ }^{1}$ Russian Federation, L.V. Kirensky Institute of Physics SB RAS, 660036, Krasnoyarsk, Akademgorodok, 50/38 \\ ${ }^{2}$ Russian Federation, Siberian Federal University, 660041, Krasnoyarsk, Svobodny st., 79. \\ ${ }^{3}$ Russian Federation, Lavrentyev Institute of Hydrodynamics SB RAS, Novosibirsk 630090, Novosibirsk, pr. ac. \\ Lavrentyeva, 15
}

Correspondence: V. P. Isakov, Russian Federation, Siberian Federal University, 660041, Krasnoyarsk, Svobodny st., 79. E-mail: isakov42@bk.ru

Received: November 12, 2014 Accepted: November 24, 2014 Online Published: December 19, 2014

doi:10.5539/ijc.v7n1p1 URL: http://dx.doi.org/10.5539/ijc.v7n1p1

\begin{abstract}
Acetylacetonates of platinum group metals $\left(\mathrm{M}(\mathrm{acac})_{\mathrm{n}}\right.$, acac $=\mathrm{CH}_{3} \mathrm{COCHCOCH}_{3}, \mathrm{n}$ - oxidation state of metal) are the most suitable precursors for use in highly effective MOCVD (metal-organic chemical vapor deposition) processes because of their thermal properties, low price of initial ligand and accessible synthesis methods. In this study we have developed a simple, scalable inexpensive, MOCVD-like approach to the deposition of Pt and Pd nanoparticle dispersions on powder detonation nanodiamonds (DND) using combustion in air of powder mixtures of DND with Pt and Pd acetylacetonates. This one-step process requires no specialized apparatus, and is conducted at mild temperatures $\left(180^{\circ} \mathrm{C}-250^{\circ} \mathrm{C}\right)$. The substrate surface of DND initiates chemical thermal destruction of precursor and deposition of nanoparticle networks composed of constituent particles. DND-supported Pd and Pt nanoparticles with their loading being from 10 and $5 \mathrm{wt}$. \% were obtained the average of particle size 20-25 nm and 7-10nm decreases with decreasing the metal loading. For additional purification and disaggregation of the commercial detonation-synthesized nanodiamond $\left(\mathrm{DND}_{\mathrm{comm}}\right)$ the method of annealing of the powder mixtures $\mathrm{DND}_{\text {comm }}$ with $\mathrm{Na}(\mathrm{acac})$ have been used. The purified diamond nanoparticulates (DND), as well as $\mathrm{DND}_{\text {comm }}, \mathrm{Pt} / \mathrm{DND}$ and $\mathrm{Pd} / \mathrm{DND}$, were subjected to physicochemical characterizations, such as X-ray diffraction (XRD), scanning electron microscopy (SEM), and energy dispersive X-ray (EDX) analysis.
\end{abstract}

Keywords: detonation-synthesized nanodiamond supports, platinum and palladium nanoparticles, combustion, chemical modification, DND additional purification

\section{Introduction}

Detonation-synthesized nanodiamond is a low-dimensional carbon nanomaterial, along with fullerene nanotubes and nanofibers. It possesses the properties of a diamond, for example, the outstanding hardness and antiwear, as well as the features of a nanoscale material, such as an ultrafine particle size and a giant specific surface area as well as a large number of surface defects (Dolmatov, 2007; Mochalin, Shenderova, Ho Dean \& Gogotsi, 2012). DND with a large specific surface area (Spitsyn et al., 2010) has great potential in the development of new types of composite materials (Gibsn et al., 2009), especially as a substrate for hosting metal nanoparticles (Panich et al., 2009). Recent works showed a number of potential DND applications. One of the most important is use nanodiamonds as a platinum group metal catalyst carrier, which is intended for application in fuel cell electrodes, electrochemical gas sensors and other electrochemical devices. The efficiency of the detonation nanodiamonds as a support for catalytic metals of platinum groups has been stated (Kachevskii, Golubina, Lokteva \& Lunin, 2007; Vershinin et al., 2011; Magdalinova, Kalmykov \& Klyuev, 2014; Fang Gao, Nianjun Yang \&Nebel, 2013).

The conventional techniques for preparing nanodiamond as a catalyst carrier of Pt-metals are wet impregnation and chemical reduction of salts/acids metal precursors $\left(\mathrm{H}_{2} \mathrm{PtCl}_{6} \mathrm{H}_{2} \mathrm{PdCl}_{4} \mathrm{RhCl}_{3}\right.$ ) (Vershinin \& Efimov, 2009; La-Torre-Riveros et al., 2011), alternative synthesis methods is based on microwave-heating of $\mathrm{H}_{2} \mathrm{PtCl}_{6}$ solution (L.Y. Bian, Y.H.Wang, J.B. Zang, F.W. Meng \& Y.L. Zhao, 2012). One of the most important drawbacks in the classical preparation of wet procedures is the stepwise nature of the process, in which a slight change in any of the parameters, at any stage, may lead to drastic changes in the characteristics and performances of the resulting 
materials. In contrast to conventional multi-step wet chemistry techniques, the MOCVD method (metal-organic chemical vapor deposition) (Serp et al., 1999; Vahlas, Juares, Feurer, Serp \& Caussat, 2002; Aksoylu et al., 2003; Vahlas, Caussat, Serp \& Angelopoulos, 2006) and flame technology (Strobel, 2009; Choi, Lee H, Shim \& Lee D., 2010; Sudong Yang et al., 2014) allow preparation of supported of metal nanoparticles of platinum group metals onto nanocarbon supports in a single step. MOCVD methods and traditional flame synthesis rely on volatile metal precursors. Now the great number of volatile metalorganic Pt-metal complexes are known, the analysis of their thermal properties is presented in (Vargas Garcia \& Takashi Goto, 2003; Morozova et al., 2001). In a number of recent works in obtaining supported on nanocarbon carriers Pt and Pd nanoparticles volatile acetylacetonates of these metals were used. In (Papandrew et al., 2013; Papandrew et al., 2013; Alexander B. Papandrew, Calum R.I. Chisholm, Ramez A. Elgammal, Mustafa M. Özer \& Strahinja K. Zecevic, 2013) platinum nanoparticles with sizes approximately $3 \mathrm{~nm}$ were deposited on carbon nanotubes by metal-organic chemical vapor deposition of platinum acetylacetonate. For the production of supported on carbon agglomerates $\mathrm{Pt}$ particles $(2-7 \mathrm{~nm}) \mathrm{Pt}(\mathrm{acac})_{2}$ -containing xylene droplets are injected into the acetylene-air flame (Choi, Lee H, Shim \& Lee D., 2010). The graphene-supported monodisperse Pd nanoparticles were prepared by simultaneous reduction of graphene oxide and $\mathrm{Pd}(\mathrm{acac})_{2}$ in flame technology so-called flame-spray pyrolysis (Sudong Yang et al., 2014).

In our studies (Isakov, Lyamkin \& Isakova, 2006; Isakova, Petrakovskaya, Isakov, Bayukov \& Velikanov, 2006) it has been shown for the first time that the powder mixture of detonation nanodiamonds with metal acetylacetonates ignites spontaneously when heated in air at temperatures lower than $200^{\circ} \mathrm{C}$. A similar reaction was observed by us for the powder mixtures of metal acetylacetonates with fullerite and taunitom (Isakova et al., 2013). Platinum metal acetylacetonates separate out metal in the condensable phase. Moreover, the addition of metal acetylacetonate in the diamond-carbon detonation charge (DC-charge) initiates spontaneous combustion and low-temperature combustion in mode of smoldering, as a result bulk of "non-diamond" fraction in the DC-charge is burned. After subsequent liquid-phase acid purification of residuum selected DND has a higher purity than DND, purified by conventional methods of liquid-phase purification (Isakova \& Isakov, 2004).

In this study, Pt and Pd nanoparticles were deposited on DND powders using self-developed one-step synthesis method i.e. the combustion in air of solid-phase mixtures of DND with Pt and Pd acetylacetonates. To remove a non-vanishing amount of residual metal impurities in commercial detonation nanodiamonds $\left(\mathrm{DND}_{\text {comm }}\right)$ the mixture of $\mathrm{DND}_{\text {comm }}$ with sodium acetylacetonate was annealed.

\section{Experimental Part}

$\mathrm{DNA}_{\text {comm }}$ produced by the Altai Federal Scientific and Production Center (Biisk), was used as an object of study. Metal acetylacetonates were obtained using the known techniques. $\mathrm{Pd}(\mathrm{acac})_{2}$ was prepared by the method which is described in (Filatov, Basova \& Igumenov, 2008). Platinum acetylacetonate $\mathrm{Pt}(\mathrm{acac})_{2}$ was synthesized in the Institute of Inorganic Chemistry of SB RAS (Novosibirsk) according to the method (Igumenov, Mikheev, Zherikova, Morozova \& Zharkova). Salts were purified from impurities by the sublimation method.

The powder mixtures of the purified detonation nanodiamond (DND) with $\mathrm{Pt}(\mathrm{acac})_{2}$ or $\mathrm{Pd}(\mathrm{acac})_{2}$ in an amount of 5 and $10 \mathrm{wt} . \%$ of the metal relative to DND were placed in flat-bottomed crucibles and heated on electric stove at temperature $\sim 250^{\circ} \mathrm{C}$ up to spontaneous ignition of powder mixture, which is observed at temperature $180^{\circ} \mathrm{C}$, and then heating was stopped, the process proceeded spontaneously in the smoldering regime with increasing temperature up to $\sim 250^{\circ} \mathrm{C}$. The smoldering temperature of powder mixtures was measured by a thermocouple (accuracy $\pm 5^{\circ} \mathrm{C}$ ). For the obtainig of the purified detonation nanodiamond the powder of $\mathrm{DND}_{\text {comm }}$ was ground in a mortar with $\mathrm{Na}(\mathrm{acac})(\sim 20 \mathrm{wt} . \%)$, and the obtained mixture was heated up to the smoldering combustion. With finishing of the combustion, the obtained powder was boiled in $\mathrm{HCl}$ solution and the color solution was removed after settling. The residuum was washed with distilled water and dried in air at $90^{\circ} \mathrm{C}$.

The characterization of the prepared samples of DND, Pt/DND and Pd/DND was performed by X-ray diffraction (XRD) (Bruker D8 Advance), energy dispersive X-ray (EDX) analysis (LEO-420 and INCA x - sight), scanning electron microscopy (SEM) (Hitachi S5500), and particle size distribution measurements (CPS Disc Centrifuge Model DC 24000).

\section{Results and Discussion}

According to (Tsiganova \& Dyagileva, 1996). Reactivity of $\beta$ - diketonates in the reaction of thermal decomposition in the case of metal acetylacetonates thermal decomposition in a vacuum into the gas phase either thermally stable Hacac or acac- radical is released. Oxygen reduces the temperature of $M(a c a c)_{n}$ disintegration and can affect the composition of the condensed phase, in the gas phase Hacac and acac oxidation products predominate $\mathrm{CO}$ and $\mathrm{CO}_{2}$. 
When heating the powder mixtures of DND with $\mathrm{Pt}(\mathrm{acac})_{2}, \mathrm{Pd}(\mathrm{acac})_{2}$ and $\mathrm{Na}(\mathrm{acac})$ in air, the spontaneous ignition of the mixtures occurs at $180-200^{\circ} \mathrm{C}$, and then the combustion process develops over the entire reaction mixture in the smoldering regime. In the absence of DND, the platinum and palladium acetylacetonates, being volatile (Vargas Garcia \& Takashi Goto, 2003; Morozova et al., 2001), are completely sublimated within the temperature range where the spontaneous ignition of their mixtures with DND occurs, while $\mathrm{Na}(\mathrm{acac})$ does not undergo substantial changes. The average ignition temperature of the DND mixtures with $\mathrm{M}(\mathrm{acac})_{\mathrm{n}}$ is lower than the temperature of their own pyrolysis of the metal salts (Tsiganova \& Dyagileva, 1996), indicating the catalytic character of the reaction. In this case, the mechanism of DND catalytic action is most likely because of their ability to adsorb oxygen on the surface.

The exothermal chemical reaction in the $\mathrm{Pt}(\mathrm{acac})_{2} / \mathrm{DND}$ and $\mathrm{Pd}(\mathrm{acac})_{2} / \mathrm{DND}$ systems proceeds on the interface of solid DND particles with metal salt vapor. The mass transfer is made by the metal salt vapors. The role of the metal acetylacetonate in the spontaneous combustion, we believe, comes down to that on the bottom surface, due to the adsorbed oxygen, they accelerates the thermal decomposition reaction of $\mathrm{M}(\mathrm{acac})_{\mathrm{n}}$ and the exothermic oxidation of released Hacac and acac. In addition, it is possible, that the process becomes autocatalytic nature by the catalytic action of precipitated metal particles.

The reaction between the $\mathrm{Na}$ (acac) powders being mixed with DND proceeds on the solid particle interface. According to the evidence observed, the process of DND combustion with the metal acetylacetonates can be attributed to the OSHS (organic self-propagating high temperature synthesis) processes described in literature (Klimchuk, 2000).

A relatively low temperature of the thermal process, regardless of the red glow being observed, can be accounted for by small-sized local regions of overheating (hot spots) appearing upon catalytic thermo-oxidative destruction of $\mathrm{M}(\mathrm{acac})_{\mathrm{n}}$, where the exothermal reaction occurs. Detonation nanodiamonds generally have low thermal conductivity (Vereschagin, 2005) due to the gases being adsorbed on the particle surface. Therefore, while the heat is released in the hot spots, DND does not have enough time to heat up and oxidize. Thus, the average temperature of the reaction mixture can be lower than that in the hot spots.

Detonation-synthesized nanodiamond particles are enclosed in amorphous carbon or graphite. Even if the particles are purified, the metal impurities can be found inside the nanodiamond aggregates, so the nanodiamond aggregates should be disintegrated to remove the trapped impurities (Kulakova, 2004).

To additionally purify $\mathrm{DND}_{\text {comm }}$ from metal impurities the mixture of $\mathrm{DND}_{\text {comm }}$ with $\mathrm{Na}$ (acac) was annealed in air in the combustion regime (Scheme 1) and after annealing the desorbed metal impurities were transformed into soluble salts.

Scheme 1: Additionally purify $\mathrm{DND}_{\text {comm }}$ from metal impurities.

$$
\begin{gathered}
\text { Air } \\
\mathrm{DND}_{\text {comm }}+\mathrm{Na}(\text { acac }) \rightarrow \mathrm{DND}+\mathrm{Na}_{2} \mathrm{O}+\left(\mathrm{M}_{\text {impur. }}\right)_{\mathrm{x}} \mathrm{O}_{\mathrm{y}}+\text { gas-phase products } \\
\text { combustion, } \mathrm{T} \sim 200-250^{\circ} \mathrm{C}
\end{gathered}
$$

Energy dispersive X-ray spectra (EDX) of the DND $_{\text {comm }}$ and DND samples are summarized in Fig. 1a and Fig. $1 \mathrm{~b}$, respectively, and data on their chemical composition are given in Table 1 . As can be seen, the $\mathrm{DND}_{\text {comm }}$ sample contains besides $\mathrm{C}$ some impurities of $\mathrm{O}, \mathrm{Al}, \mathrm{Si}, \mathrm{Fe}$. Only $\mathrm{C}$ and $\mathrm{O}$ are detected for the DND sample. The oxygen content is reduced (see Table 1). This may be related with changes in the composition of the DND surface groups.

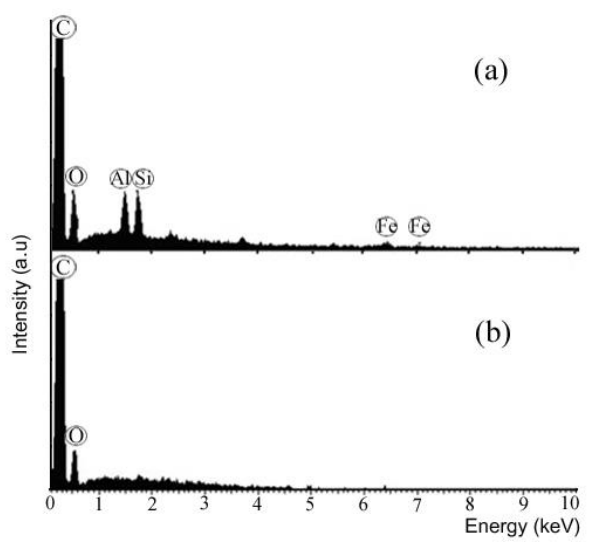


Figure 1. The energy dispersive $\mathrm{X}$-ray spectrum: a) $\left.\mathrm{DND}_{\text {comm }}, \mathrm{b}\right) \mathrm{DND}$

Table 1. The elemental analysis of $\mathrm{DND}_{\text {comm }}$, DNA

\begin{tabular}{lllll}
\hline Element & \multicolumn{2}{c}{ Wt.\% } & \multicolumn{2}{c}{ Atom.\% } \\
\hline & DND $_{\text {comm }}$ & DNA & DND $_{\text {comm }}$ & DNA \\
\hline $\mathrm{C}$ & 87.55 & 91.32 & 90.97 & 93.34 \\
$\mathrm{O}$ & 10.58 & 8.68 & 8.25 & 6.66 \\
$\mathrm{Al}$ & 0.74 & & 0.34 & \\
$\mathrm{Si}$ & 0.8 & & 0.36 & \\
$\mathrm{Fe}$ & 0.33 & & 0.07 & \\
\hline
\end{tabular}

The EDX spectrum (Fig.2) of the combustion product of DND/ Pt(acac) $)_{2}$ (5 wt.\% Pt relative to the nanodiamond) shows only C and Pt. Oxygen is not detected, likely due to its low content. The platinum content (see Table 2) in the Pt/DND sample (4.94\%) corresponds to the nanodiamond/platinum ratio in the initially prepared mixture of $\mathrm{Pt}(\mathrm{acac})_{2} / \mathrm{DND}$. The measured masses of the combustion products of the $\mathrm{DND} / \mathrm{Pt}(\mathrm{acac})_{2}$ and $\mathrm{DND} / \mathrm{Pd}(\mathrm{acac})_{2}$ mixtures correspond to the total weight of DND and the metal in the initial mixtures.

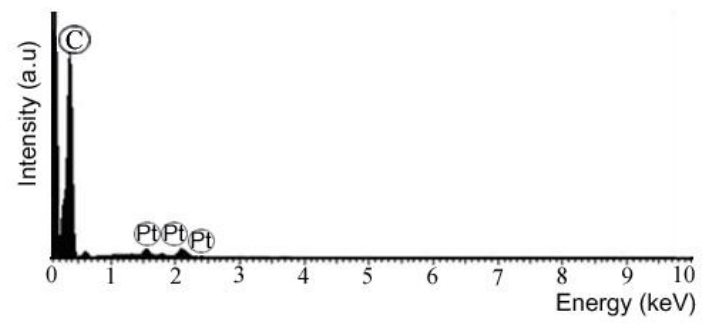

Figure 2. The energy dispersive X-ray spectrum, Pt/DND

Table 2. The elemental analysis of Pt/DND

\begin{tabular}{lll}
\hline Element & Wt.\% & Atom.\% \\
\hline $\mathrm{C}$ & 95.06 & 99.68 \\
$\mathrm{Pt}$ & 4.94 & 0.32
\end{tabular}

The powder XRD patterns for the Pt/DND and Pd/DND samples with the metal loading of $5 \mathrm{wt} . \%$ and $10 \mathrm{wt} . \%$, are shown in Fig. 3, 4.

The XRD patterns confirm the presence of crystalline Pt and Pd nanoparticles with characteristic peaks at $2 \Theta$ values of (Pt): $39.8^{\circ}, 46.2^{\circ}, 67.4^{\circ}, 81.2^{\circ}, 85.8^{\circ}$ (Fig. 3); and of (Pd): $40.1^{\circ}, 48.7^{\circ}, 68.2^{\circ}, 82.2^{\circ}, 86.6^{\circ}$ (Fig. 4),

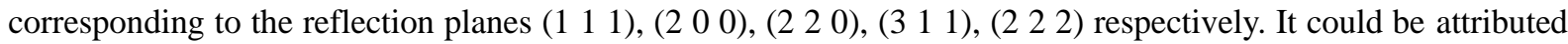
to face-centered cubic Pt and Pd. The peaks appear at $2 \Theta 33.9^{\circ}, 54.7^{\circ}, 71.4^{\circ}$ (Fig. 4) corresponding to PdO. The partial formation $\mathrm{PdO}(\sim 2-3 \%)$ is likely to be due to Pd high reactivity as compared to Pt. The peak broadening evidences the nanoscale dimensionality of the $\mathrm{Pt}, \mathrm{Pd}$ and $\mathrm{PdO}$ particles.

The diffraction peaks observed at $2 \Theta 43.98^{\circ}, 75.28^{\circ}$, and $91.68^{\circ}$ are attributed to the cubic diamond planes $(11$ 1), (2 20 ), and (3 11 ), respectively. With the Pt and Pd loading increasing, the intensity of the diffraction peaks of the nanodiamond decreases. This implies more metal nanoparticles being deposited on the nanodiamond surface.

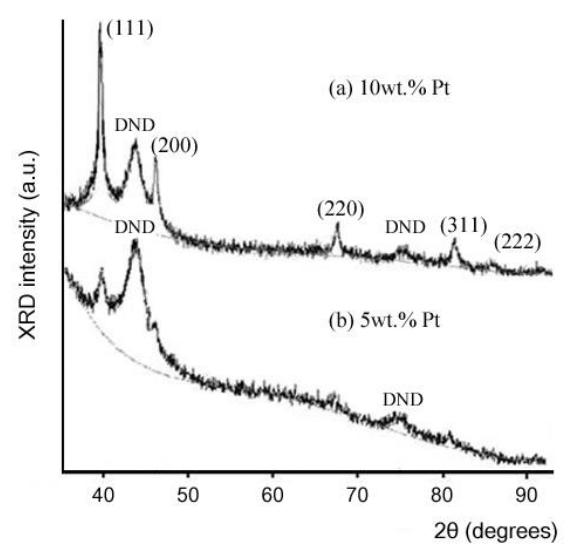


Figure 3. The XRD patterns of Pt/DND: a) at $10 \mathrm{wt} . \% \mathrm{Pt}$; b) at $5 \mathrm{wt} . \% \mathrm{Pt}$

The crystallite size of Pt and Pd is found to be dependent on the metal loading, indicating better dispersion of the $\mathrm{Pt}$-metal particles on the DND support at lower Pt-metal loading.

For the metal loading of $10 \mathrm{wt} . \%$ and $5 \mathrm{wt} . \%$, the average Pt and Pd crystalline particle sizes evaluated using the Scherrer method were about $25 \mathrm{~nm}$ and $10 \mathrm{~nm}$, respectively.

The simultaneous loading of Pd and PdO nanoparticles on the DND surface is of interest. For example, it is shown (Aramendia et al., 1999; Golubina, Lokteva, Majouga, Lobanov \& Lunin, 2011; Magdalinova, Kalmykov \& Klyuev, 2012) that upon the formation of a high-effective Pd catalyst the structure of the active center is to contain both the reduced and the oxidized metal. However, in the common Pd catalyst preparation processes the reduction stage is always present, with a partially oxidized metal being difficult to obtain in this case.

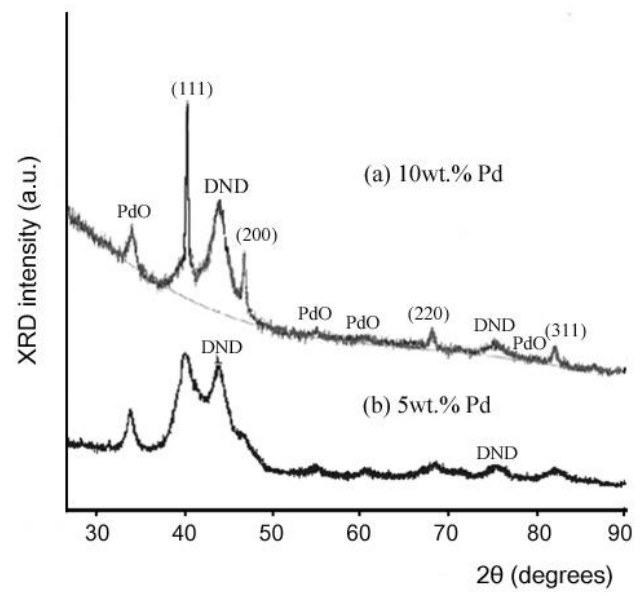

Figure 4. The XRD patterns of Pd/DND: a) at 10wt.\% Pd (PdO- 2,07\%); b) at 5wt.\% Pd

It is known that nanodiamonds prepared by explosive detonation have primarily the particles, $4 \sim 6 \mathrm{~nm}$ in diameter, but they undergo severe aggregation, forming aggregates of hundreds of $\mathrm{nm}$, even several $\mu \mathrm{m}$ in diameter, which can withstand ultrasonic treatment (Kriiger et al., 2005). The details of the surface morphology of the $\mathrm{DND}_{\text {comm }}$, and the prepared $\mathrm{DND}, \mathrm{Pt} / \mathrm{DND}, \mathrm{Pd} / \mathrm{DND}$ samples were obtained using scanning electron microscopy (SEM).

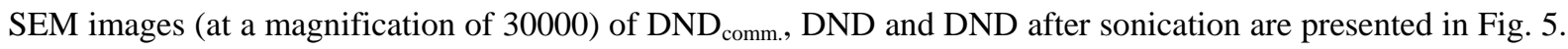
It can be seen from the micrographs that the $\mathrm{DND}_{\text {comm. }}$ aggregates with diameter more than $1 \mu \mathrm{m}$ (Fig. $5 \mathrm{a}$ ) can form DND aggregates with diameter less than 200-250 nm after annealing with $\mathrm{Na}$ (acac) (Fig. 5b) and the DND aggregates are broken down to aggregates of about $30-10 \mathrm{~nm}$ after the sonication (Fig. 5c)
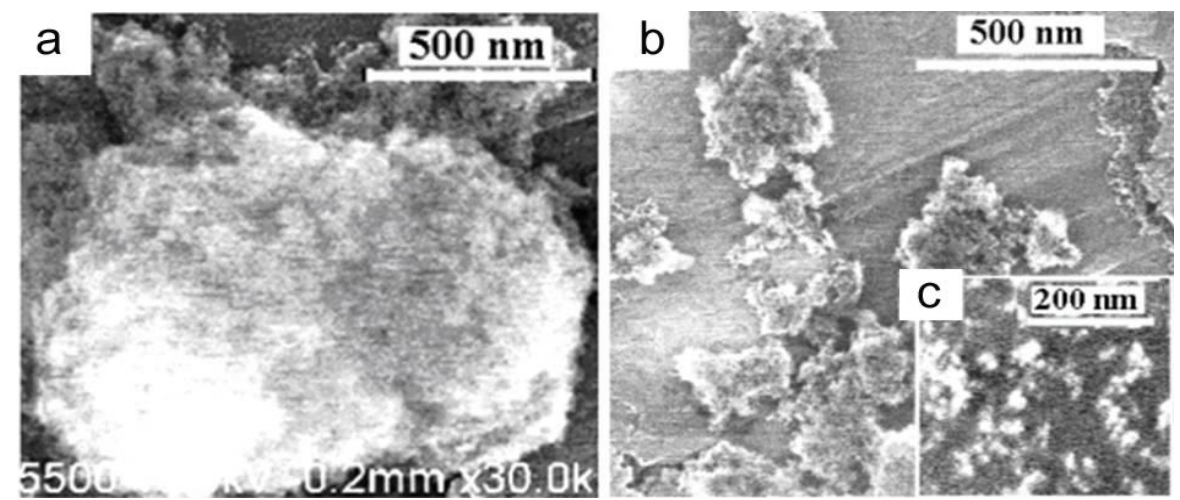

Figure 5. The micrographs: a) the aggregated $\mathrm{DND}_{\text {comm }}$ particles, b) the aggregated DND particles, c) the aggregated DND particles after sonication

The particle-size distribution curves of $\mathrm{DND}_{\text {comm }}$ after sonication (Fig 6a in the inset) as well as the DND particles after sonication (Fig. 6b) show a strong difference. The size of the DND particles is significantly reduced in comparison with the size of the $\mathrm{DND}_{\text {comm }}$ ones. Their mean particle diameters are 8-10 nm and 200$500 \mathrm{~nm}$, respectively. The particle-size distribution curves of Pd /DND (5 Wt.\% Pd ) are shown in Fig. 6c. After loading Pd on the DND surface the size of most particles of the obtained composite is about 5-7 nm. It is less, than $\mathrm{DND}_{\mathrm{s}}$ particles size. It's possible, that aggregated DND particles destruction occurs more intensive in the 
smoldering process of $\mathrm{DND}+\mathrm{Pd}(\mathrm{acac})_{2}$ powder mixture, then under ultrasonic treatment.

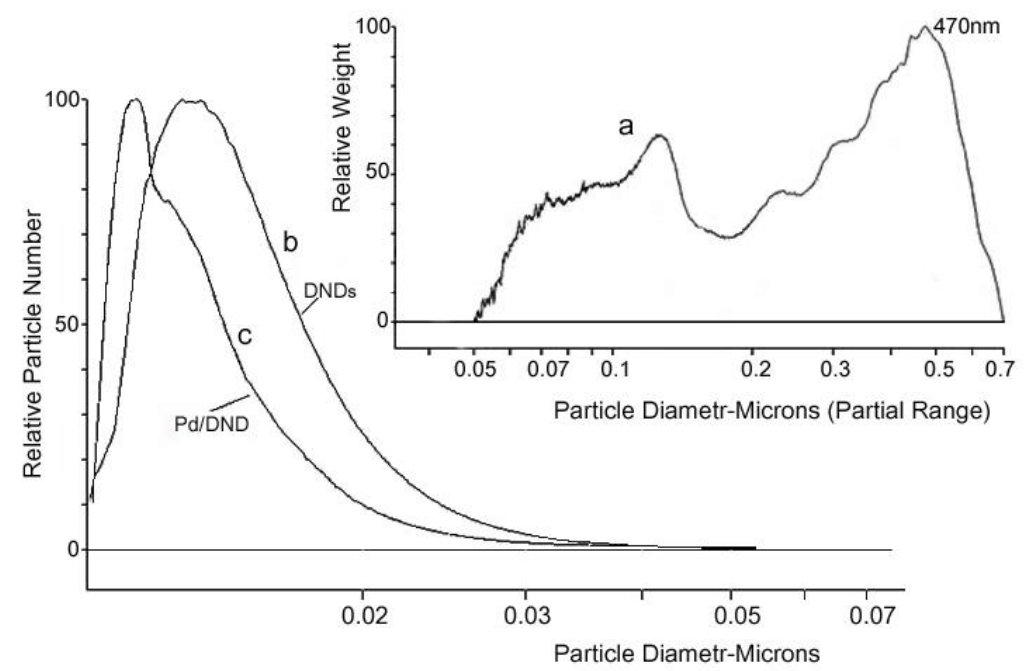

Figure 6. The dependence of the relative distribution of the particle amount on the sample size: $\mathrm{DND}_{\text {comm }}-$ curve a; DND - curve b, Pd/DND- curve c

Figure 7 presents the micrographs of DND, Pt/DND and Pd/DND at a magnification of 300000 . The formation of the DND particle aggregates of about $200 \mathrm{~nm}$ was registered (Fig. 7a). The structure of the Pd/DND and $\mathrm{Pt} / \mathrm{DND}$ surfaces reveals different morphology. As is seen, the Pd/DND and Pt/DND particles appear to have grain-like morphology, with the grains being $20-5 \mathrm{~nm}$ in size, depending on the metal loading on the DND support. With 10 wt.\% of metal in the Pt /DND (Fig. 7b) and Pd /DND samples (Fig. 7c) the grain size is equal to $\sim 20 \mathrm{~nm}$ and smaller. In the Pd /DND sample with $5 \mathrm{wt}$. \% Pd (Fig.7d) the grain size is $\sim 7 \mathrm{~nm}$ and smaller (see also Fig. 6c).
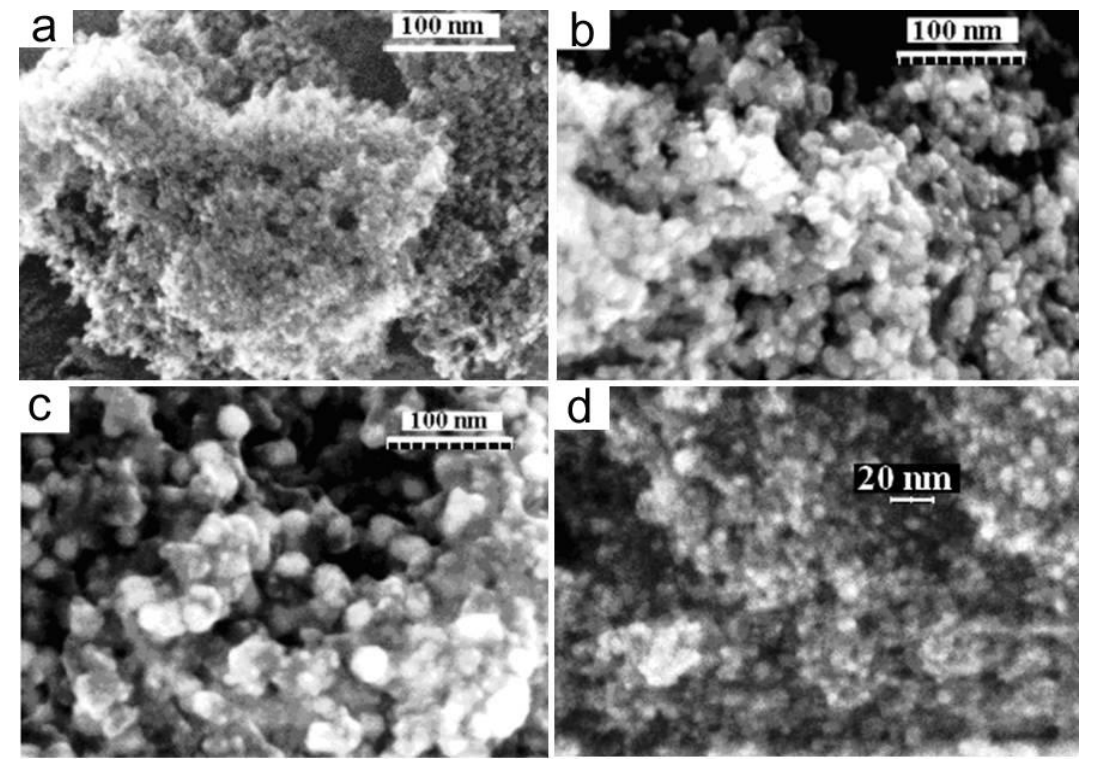

Figure 7. The micrographs: a) the aggregated DND particles, b), c) DND /Pt, DND /Pd (10wt $\%$ of the metals), d) $\mathrm{DND} / \mathrm{Pd}(5 \mathrm{wt} \% \mathrm{Pd})$

\section{Conclusion}

A one-step synthesis method to prepare Pt and Pd nanoparticles supported on the surface of detonation nanodiamond (DND) powders has been used. Metal nanoparticles were deposited on the surface of DND using the combustion in air of the powder mixtures of DND with volatile acetylacetonates of Pt and Pd. The density growth of the Pt and Pd nanoparticles on the DND support could be controlled by manipulating the mass ratios between the Pt and Pd precursor and the nanodiamond support. Scanning electron microscopy, and X-ray diffraction patterns confirm the formation of the Pt and Pd nanoparticles and the increase of the average particle 
sizes $(\approx 5-25 \mathrm{~nm})$ with increasing the metal loading. The partial oxidation of $\mathrm{Pd}(\sim 2-3 \%)$ is likely to be due to its high reactivity as compared to Pt. The thermal destruction of Pt and Pd acetylacetonates offers a simple route to prepare the dispersed Pt and Pd catalyst nanoparticles on DND surface for their possible application as an advanced electrode material in direct methanol fuel cells. Further research is needed to reduce the particle size. Annealing the commercial detonation-synthesized nanodiamond with the addition of $\mathrm{Na}$ acetylacetonates is shown to allow desorbing metal impurities which are difficult to remove during the purification of detonation nanodiamonds using conventional techniques. The annealing process is also found to allow breaking down the DND aggregates.

\section{References}

Aksoylu, A. E., Faria, J. L., Pereira, M. F. R., Figueiredo, J. L., Serp, P., Hierso, J.-C., Feurer, R., Kihn, Y., \& Kalck, P. (2003). Highly dispersed activated carbon supported platinum catalysts prepared by OMCVD: A comparison with wet impregnated catalysts. Applied Catalysis A General, 243(2), 357-365. http://dx.doi.org/10.1016/S0926-860X(02)00556-2

Aramendia, M.A., Borau, V., Garcia, I.M., Jimenez, C., Lafont, F., Marinas, A., Marinas, J.M., \& Urbano, F.J. (1999). Influence of the Reaction Conditions and Catalytic Properties on the Liquid-Phase Hydrodechlorination of Chlorobenzene over Palladium-Supported Catalysts: Activity and Deactivation. Journal of Catalysis, 187, 392-399. http://dx.doi.org/10.1006/jcat.1999.2632

Bian, L. Y., Wang, Y. H., Zang, J. B., Meng, F. W., \& Zhao, Y. L. (2012). Detonation-synthesized Nanodiamond as a Stable Support of Pt Electrocatalyst for Methanol Electrooxidation. International Journal of Electrochemical Science, 7, 7295 - 7303. http://electrochemsci.org/papers/vol7/7087295.pdf

Choi, I. D., Lee, H., Shim, Y. B., \& Lee D. (2010, July 6). A one-step continuous synthesis of carbon-supported Pt catalysts using a flame for the preparation of the fuel electrode. Langmuir, 26(13), 11212-11216. http://dx.doi.org/ 10.1021/la1005264.

Dolmatov, V. Y. (2007). Detonation synthesis nanodiamonds: synthesis, structure, properties and applications. Russian Chemical Reviews, 76, 339-360. http://dx.doi.org/10.1070/RC2007v076n04ABEH003643

Filatov, E. S., Basova, T. V., \& Igumenov, I. K. (2008). The vibrational spectra of some palladium (II) beta-diketonates and their interpretation. http://zhurnal.ape.relarn.ru/articles/2008/010.pdf

Gao, F., Yang, N., \& Nebel, Ch. E. (2013, December 1). Highly stable platinum nanoparticles on diamond. Electrochimica Acta, 112, 493-499. http://dx.doi.org/10.1016/j.electacta.2013.09.005

Gibson, N., Shenderova, O. A., Luo, T. J. M., Moseenkov, S., Bondar, V., Puzyr, A., Purtov, K. , Fitzgerald, Z., \& Brenner, D. W. (2009). Colloidal stability of modified nanodiamond particles. Diamond and Related Materials, 18(4), 620-626. http://dx.doi.org/10.1016/j.diamond.2008.10.049

Golubina, E. V., Lokteva, E. S., Majouga, A. G., Lobanov, M. V., \& Lunin, V. V. (2011). Ultradispersed diamond as an excellent support for Pd and Au nanoparticle based catalysts for hydrodechlorination and $\mathrm{CO}$ oxidation. Diamond and Related Materials, 20(7), 960-964. http://dx.doi.org/10.1016/j.diamond.2011.05.020

Igumenov, I. K., Mikheev, A. N., Zherikova, K. V., Morozova, N. B., \& Zharkova, G. I. Method of obtaining acetylacetonates of platinum group metals. Patent RU 2495880.

Isakov, V. P., Lyamkin, A. I., \& Isakova V. G. (2006). Application possibilities of explosive synthesis nanopowders. Nanotechnics, 8, 91-96.

Isakova, V. G., \& Isakov, V. P. (2004). Explosives detonation products thermal oxidation initiated by metal acetylacetonates. Solid State Physics, 46(4), 607-609.

Isakova, V. G., Isakov, V. P., Lyamkin, A. I., Petrakovskaya, E. A., Nemtsev, I. V., \& Zharikova, N. V. (2013). Platinum metal nanoparticles in the powder mixtures with nanocarbon materials. XX Int.Conf on Chemistry, Analysis and Technology of Platinum Group Metals. Krasnoyarsk, 182. ISBN 978-5-7638-2891-7.

Isakova, V. G., Petrakovskaya, E. A., Isakov, V. P., Bayukov, O. A., \& Velikanov, D. A. (2006). The research of powder fullerene and ultra-dispersed diamond composites with metal and oxide nano-particles. The Physics of Metals and Metalography, 102(1), 51-60.

Kachevskii, S. A., Golubina, E. V., Lokteva, E. S., \& Lunin, V. V. (2007, June). Palladium on ultradisperse diamond and activated carbon: the relation between structure and activity in hydrodechlorination. Russian Journal of Physical Chemistry A, 81(6), 866-873. http://dx.doi.org/10.1134/S0036024407060064 
Klimchuk, E. G. (2000). Autowave exothermic organic synthesis in the mixes of organic solids. Macromolecular symposia, 160, 107-114. http://dx.doi.org/10.1002/1521-3900(200010)160:1<107::AID-MASY107>3.0.CO;2-D

Kriiger, A., Kataoka, F., Ozawa, M., Fujino, T., Suzuki, Y., Aleksenskii, A.E., Vul', A.Ya., \& Osawa, E. (2005). Unusually tight aggregation in detonation-nanodiamond: identification and disintegration. Carbon, 43, 1722-1730.

Kulakova, I. I. (2004). Chemistry of nanodiamond surface. Solid State Physics, 46(4), 636-643. http://dx.doi.org/10.1134/1.1711440

La-Torre-Riveros, L., Abel-Tatis, E., Mendez-Torres, A., Tryk, D. A., Prelas, M., \& Cabrer, C. R. (2011). Synthesis of platinum and platinum-ruthenium-modified diamond nanoparticles. J Nanopart Res, 13, $2997-$ 3009. http://dx.doi.org/ 10.1007/s11051-010-0196-8

Magdalinova, N. A., Kalmykov, P. A., \& Klyuev, M. V. (2012). Palladium-containing nanodiamonds in hydrogenation and hydroamination. Petroleum Chemistry, 52(5), 299-304. http://dx.doi.org/10.1134/S0965544112050064

Magdalinova, N. A., Kalmykov, P. A., \& Klyuev, M. V. (2014). Hydrogenation catalysts based on platinum- and palladium-containing nanodiamonds. Russian Journal of General Chemistry, 84(1), 33-39. http://dx.doi.org/10.1134/s1070363214010083

Mochalin, V. N., Shenderova, O. A., Ho Dean, Gogotsi, \& Yu. (2012). The properties and applications of Nanodiamonds. Nature nanotechnology, 7(1), 11-23. http://dx.doi.org/10.1038/nnano.2011.209

Morozova, N. B., Zharkova, G. I., Semyannikov, P. P., Sysoev, S. V., Igumenov, I. K., Fedotova, N. E., \& Gelfond, N. V. (2001). Vapor pressure of precursors for CVD on the base of platinum group metals. Journal de Physique IV, 11, 609-616. http://dx.doi.org/SICI:1155-4339(200108)11:PR3<609:VPOPFC>2.0.ZU;2-2

Panich, A. M., Shames, A. I., Medvedev, O., Osipov, V. Yu., Aleksenskiy, A. E., \& Vul, A. Ya. (2009). Magnetic Resonance Study of Detonation Nanodiamonds with Surface Chemically Modified by Transition Metal Ions. Applied Magnetic Resonance, 36, 317-329. http://dx.doi.org/10.1007/s00723-009-0028-0

Papandrew, A. B., Atkinson III, R. W., Goenaga, G. A., Kocha, Sh. S., Zack, J. W., Pivovar, B. S., \& Zawodzinski, T. A. (2013). Oxygen Reduction Activity of Vapor-Grown Platinum Nanotubes. $J$. Electrochem. Soc., 160(8), F848-F852. http://dx.doi.org/ 10.1149/2.090308jes

Papandrew, A. B., Atkinson III, R. W., Goenaga, G. A., Wilson, D. L., Kocha, Sh. S., Neyerlin, K. C., Zack, J. W., Pivovar, B. S., \& Zawodzinski, T. A. (2013). Oxygen Reduction Activity of Vapor-Grown Platinum Nanotubes. ECS Trans, 50(2), 1397-1403. http://dx.doi.org/ 10.1149/05002.1397ecst

Papandrew, A. B., Chisholm, C. R. I., Elgammal, R. A., Özer, M. M., \& Zecevic, S. K. (2011). Advanced Electrodes for Solid Acid Fuel Cells by Platinum Deposition on CsH2PO4. Chemistry of Materials, 23(7), 1659-1667. http://dx.doi.org/ 10.1021/cm101147y

Reto, S. (2009). Flame Synthesis of Supported Platinum Group Metals for Catalysis and Sensors Platinum. Metals Rev., 53(1), 11. http://dx.doi.org/10.1595/147106709x392993

Serp, Ph., Hierso, J.-C., Feurer, R., Kihn, Y., Kalck, Ph., Faria, J. L., Aksoylu, A.E., Pacheco, A. M. T., \& Figueiredo, J. L. (1999). Single-step preparation of activated carbon supported platinum catalysts by fluidized bed organometallic chemical vapor deposition. Carbon, 37(3), 527-530. http://dx.doi.org/10.1016/S0008-6223(99)00018-4

Spitsyn, B. V., Denisov, S. A., Skorik, N. A., Chopurova, A. G., Parkaeva, S. A., Belyakova, L. D., \& Larionov, O. G. (2010). The development of physical-chemical basic for detonation diamond in adsorption and $\begin{array}{lllll}\text { chromatography. Diamond and Related } & \text { Materials, } & 19, & 127 .\end{array}$ http://dx.doi.org/10.1016/j.diamond.2009.10.020

Tsiganova, E. I., \& Dyagileva, L. M. (1996). Reactivity of $\beta$ - diketonates in the reaction of thermal decomposition. Usp Khim, 65(4), 334-349.

Vahlas, C., Caussat, B., Serp, P., \& Angelopoulos, G. (2006). Principles and applications of CVD powder technology. Mat.Sci. Eng. Reports, 53, 1-72. http://dx.doi.org/10.1016/j.mser.2006.05.001

Vahlas, F., Juarez, L., Feurer, R., Serp, Ph., \& Caussat, B. (2002). Fluidization, spouting, and metalorganic chemical vapor deposition of platinum group metals on powders. Chemical Vapor Deposition, 4, 127-144. http://dx.doi.org/10.1002/1521-3862(20020704)8:4<127::AID-CVDE127>3.0.CO;2-VC. 
Vargas Garcia, J. R., \& Goto, T. (2003). Chemical Vapor Deposition of Iridium, Platinum, Rhodium and Palladium. Materials Transactions, 44(9), 1717-1728. https://www.jim.or.jp/journal/e/pdf3/44/09/1717.pdf

Vereshchagin, A. L. (2005). Properties of detonation nanodiamond. Altai Federal Scientific (Biisk), 134.

Vershinin, N. N, \& Efimov, O. N. (2009). Catalyst and process for its preparation, Patent RU 2348090.

Vershinin, N. N., Efimov, O. N., Bakaev, V. A., Aleksenskii, A. E., Baidakova, M. V., Sitnikova, A. A., \& Vul', A. Ya. (2011). Detonation nanodiamonds as catalyst supports, Fullerenes, Nanotubes and Carbon Nanostructures, 19, 63-68. http://dx.doi.org/10.1080/1536383X.2010.490143

Yang, S., Dong, J., Yao, Z., Shen, C., Shi, X., Tian, Y., Lin, S., \& Zhang, X. (2014). One-Pot Synthesis of Graphene-Supported Monodisperse Pd Nanoparticles as Catalyst for Formic Acid Electro-oxidation. Sci Rep., 4, 4501. http://dx.doi.org/ 10.1038/srep04501

\section{Copyrights}

Copyright for this article is retained by the author(s), with first publication rights granted to the journal.

This is an open-access article distributed under the terms and conditions of the Creative Commons Attribution license (http://creativecommons.org/licenses/by/3.0/). 